\title{
Serum Amylin Indicates Hypertriglyceridemia in Pre-diabetics
}

Leonardo M Porchia1, Enrique Torres-Rasgado ${ }^{2,5}$, Elba Gonzalez-Mejia M², Ricardo Perez-Fuentes ${ }^{1,2 *}$, Alicia Rivera ${ }^{3}$, Martha RodriguezMoran $^{4}$, Fernando Guerrero-Romero ${ }^{4}$ and Jose R Romero ${ }^{5}$

${ }^{1}$ Laboratorio de Fisiopatología en Enfermedades Crónicas, Centro de Investigación Biomédica del Oriente, IMSS, Puebla, Mexico

${ }^{2}$ Facultad de Medicina, Benemérita Universidad Autónoma de Puebla, Puebla, Mexico

${ }^{3}$ Department of Laboratory Medicine, Boston Children's Hospital and the Department of Pathology, Harvard Medical School

${ }^{4}$ Biomedical Research Unit, Mexican Social Security Institute at Durango, Mexico

${ }^{5}$ Division of Endocrinology, Diabetes and Hypertension, Brigham and Women's Hospital, and the Department of Medicine, Harvard Medical School, Boston, MA, USA

\begin{abstract}
Background: Hypertriglyceridemia is associated with increased insulin secretion and the incidence of Type 2 Diabetes. Studies in rodents and obese children have proposed a relationship between hypertriglyceridemia and elevated plasma amylin levels. However, there are limited data regarding serum amylin and triglyceride levels in adult human subjects with impaired glucose tolerance. In this study, we evaluated the association between serum triglycerides with circulating amylin levels in adult subjects with and without impaired glucose tolerance.
\end{abstract}

Methods: Glucose, insulin, Hemoglobin A1c, triglycerides, total amylin and unreduced amylin levels were determined in 80 non-pregnant females and 60 males enrolled in a cross-sectional study. Subjects were allocated according to their glucose tolerance status into normal glucose tolerance $(n=81)$ and impaired glucose tolerance $(n=59)$. Subjects with Type 2 Diabetes, endocrine diseases, chronic inflammation or inflammatory diseases, as well as alcoholism were excluded. Correlation and sensitivity between triglycerides and amylin was investigated using Pearson's correlation coefficient $(r)$ and Receiver-Operating Characteristics (ROC) curve, respectively.

Results: Serum triglycerides strongly correlated with only total amylin $(r=0.470, p<0.05)$ in the impaired glucose tolerance group and not the normal glucose tolerance group. No correlation between triglycerides and unreduced amylin was observed in neither group. The area under the ROC curve (AUC) was only significant for hypertriglyceridemia and total amylin in the impaired glucose tolerance group (AUC $=0.731,95 \% \mathrm{Cl}: 0.600-0.838$, $\mathrm{p}<0.05)$.

Conclusion: Our results suggest that serum triglycerides and total amylin levels are significantly associated in impaired glucose tolerance subjects.

Keywords: Total amylin; Unreduced amylin; Hypertriglyceridemia; Pre-diabetes; IAPP

\section{Introduction}

Islet amyloid polypeptide (IAPP or amylin) is a 37 amino acid residue hormone expressed mainly by pancreatic islet $\beta$-cells. It is well-known for its ability to aggregate into amyloid fibrils in islets of Langerhans leading to loss of $\beta$-cells function [1-3], a step that is crucial in the progression from pre-diabetes to Type 2 Diabetes. Amylin, which is co-secreted with insulin, regulates post-prandial glucose levels in part by inhibiting gastric emptying and suppressing glucagon release while not affecting glucose uptake [4]. Amylin has been shown to mirror insulin secretion in healthy subjects [5], obese subjects, prediabetics (subjects with impaired glucose tolerance) [6,7], and patients with Type 2 Diabetes [5]. These findings suggest an active role for plasma amylin levels in modulating glucose metabolism [8]. However, the mechanisms and the precise role of amylin in the pathophysiology of Type 2 Diabetes remains unclear.

There have been multiple forms of amylin detected in plasma: unreduced amylin (presence of a disulfide bond between amino acid 2 and 7), reduced amylin, and amylin acid (deamidated amylin) [9]. Experimental studies have shown that infusion of amylin into rats lead to elevated triglyceride content in liver and muscle tissue [10] and that infusion of amylin-(8-37), a specific amylin antagonist, reduced muscle triglycerides. Mice, on a long-term high-fat diet, showed augmented amylin levels [1]. Indeed, the free fatty acids palmitate and oleate have been shown to increase amylin expression [11]. Amylin, in turn, blocked glucose disposal by liver cells [12] and exerted a lipolyticlike action leading to increased plasma non-esterified fatty acids and glycerol levels [10]. These results strongly suggest an important relationship among triglycerides, free fatty acids, and amylin release.

Hypertriglyceridemia has been associated with increased insulin secretion in non-obese subjects, pre-diabetics [13,14], and patients with Type 2 Diabetes $[15,16]$. These results support the contention that hypertriglyceridemia may be related to amylin secretion. However, reports about the relationship between hypertriglyceridemia and plasma amylin levels are scarce $[6,10,17]$. Taken together, these observations prompted us to evaluate the association between serum triglycerides with circulating amylin levels among subjects with and without impaired glucose tolerance.

\section{Material and Methods}

\section{Subjects and settings}

Following approval from the Scientific Research and Ethics

*Corresponding author: Ricardo Pérez-Fuentes, Laboratorio de Fisiopatología en Enfermedades Crónicas, Centro de Investigación Biomédica del Oriente, IMSS Puebla, Mexico, Tel: +52 24444 122; E-mail: rycardoperez@hotmail.com

Received December 15, 2014; Accepted January 12, 2015; Published January 25, 2015

Citation: Porchia LM, Torres-Rasgado E, Gonzalez-Mejia ME, Perez-Fuentes R, Rivera A, et al. (2015) Serum Amylin Indicates Hypertriglyceridemia in Prediabetics. J Diabetes Metab 6: 509. doi:10.4172/2155-6156.1000509

Copyright: () 2015 Porchia LM, et al. This is an open-access article distributed under the terms of the Creative Commons Attribution License, which permits unrestricted use, distribution, and reproduction in any medium, provided the original author and source are credited. 
Committees of the Mexican Social Security Institute (IMSS) and the written informed consent of participants in accordance with the Declaration of Helsinki, a cross-sectional study was carried out. The study included males $(\mathrm{n}=60)$ and non-pregnant females $(\mathrm{n}=80)$, aged 18 to 77 years-old. The subjects were from urban and rural communities from Puebla, Mexico and met the following criteria: healthy and without Diabetes. Subjects were excluded from the study if they had other endocrine diseases, chronic inflammation or inflammatory diseases, as well as alcoholism.

\section{Clinical characterization}

Subjects were clinically evaluated according to a standardized protocol including personal and family history. In the standing position, weight and height were measured with the subjects in light clothing and without shoes using a fixed scale with stadimeter (Tanita TBF-215, Tokyo, Japan). Body Mass Index (BMI) was calculated as weight (kilograms) divided by height (meters) squared. BMIs $<18.4$ $\mathrm{Kg} / \mathrm{m}^{2}$ and $>40 \mathrm{Kg} / \mathrm{m}^{2}$ were excluded. Total body fat was measured by bioelectric impedance using a body composition analyzer (Tanita TBF-215, Tokyo, Japan). Blood pressure was measured according to the recommended technique in the Sixth Report of the Joint National Committee on Prevention, Detection, Evaluation, and Treatment of High Blood Pressure [18]. The data is the average of two physicianobtained measurements.

\section{Biochemical assays}

Venous blood samples were collected into EDTA containing tubes after an overnight fasting of 10 to 12 hours. Blood samples were used for the follow endpoints: fasting glucose and insulin, oral glucose tolerance test (Glucose 2-h post load), Hemoglobin A1c, amylin (total and unreduced-form), and triglycerides. A new blood samples were obtained $2 \mathrm{~h}$ after oral glucose administration (75 gr) to determine the Glucose 2-h post load. Fasting glucose and Glucose 2-h postload were determined, in duplicate, using the enzymatic method/ spectrophotometric glucose oxidation (Beckman Instruments, Brea, CA). Fasting insulin levels were determined by chemiluminescent immunoassay (Abbott). The Hemoglobin Alc levels were determined by the turbidimetric inhibition immunoassay. Plasma amylin levels were measured by ELISA following manufacturer's instructions (Millipore, Billerica, MA [EZHAT-51K for total amylin and EZHA$52 \mathrm{~K}$ for unreduced form]). Total amylin corresponds to the unreduced and reduced forms, whereas the unreduced amylin corresponds to only the unreduced form. The sensitivity of the assay was $1 \mathrm{pM}$ for amylin in our hands. The coefficient of variation of amylin was $1.8 \%$. High and low control samples were run simultaneously with values accepted only when control values were within this range. Triglycerides were enzymatically measured using spectrophotometric methods; the intraand inter-assay coefficients of variation were $1.7 \%$ and $3.1 \%$. Normal values for triglycerides $(<150 \mathrm{mg} / \mathrm{dL})$ were defined according to NOM037-SSA2-2002 [19].

\section{Definitions}

Using the American Diabetes Association recommendation [20], subjects were classified as either impaired glucose tolerance (fasting glucose: 100-126 mg/dL, Glucose 2-h postload: 140-200 $\mathrm{mg} / \mathrm{dL}$, or Hemoglobin A1c: 5.7-6.4\%) or normal glucose tolerance (fasting glucose: $<100 \mathrm{mg} / \mathrm{dL}$, Glucose 2 -h postload: $<140 \mathrm{mg} / \mathrm{dL}$, or Hemoglobin A1c: $<5.7 \%)$.

\section{Statistical analysis}

Statistical analyses were performed using Statistical Package for the Social Sciences program for Windows, version 19 (SPSS, Chicago, IL) or Medcalc Statistical Software version 13.3.3 (Medcalc, Ostend, Belgium). Differences between groups were evaluated using Student T-test. The results were expressed as mean \pm standard error (SPSS). Correlation analysis was done by calculating the Pearson's correlation coefficient (r). Receiver Operating Characteristic (ROC) curve was used to determine the sensitivity and specificity of amylin to determine hypertriglyceridemia. The area under the ROC curve (AUC) was calculated using the method described by Hanley and McNeil [21] (Medcalc). p-values $<0.05$ were considered statistically significant.

\section{Results}

A total of 80 non-pregnant females (57.1\%) and 60 males (42.9\%) were enrolled; of these, $81(57.9 \%)$ and 59 (42.1\%) were allocated into the normal glucose tolerance group and the impaired glucose tolerance group, respectively. The clinical and metabolic characteristics are summarized in Table 1. There was no difference in triglycerides, total amylin, or unreduced amylin concentrations between the normal glucose tolerance group and the impaired glucose tolerance group. However, when the relationship between triglycerides and total amylin levels was determined, only the impaired glucose tolerance group demonstrated a strong correlation $(\mathrm{r}=0.470, \mathrm{p}<0.05$, Figure $1 \mathrm{~B})$. No correlation between total amylin and triglycerides was seen with the normal glucose tolerance group or between unreduced amylin and triglycerides for both groups (Figure 1A, C, and D). For total amylin, the impaired glucose tolerance group did specifically determine hypertriglyceridemia (AUC=0.731, 95\% CI: 0.600-0.838, $\mathrm{p}<0.001$, Figure $2 \mathrm{~B}$ ), which was not seen with the normal glucose tolerance group (AUC=0.587, 95\% CI: 0.472-0.635, $\mathrm{p}=0.185$, Figure $2 \mathrm{~A}$ ). With both groups, unreduced amylin could not specifically determine hypertriglyceridemia (normal glucose tolerance: $\mathrm{AUC}=0.605,95 \% \mathrm{CI}$ : $0.469-0.730, p=0.168$ and impaired glucose tolerance: $\mathrm{AUC}=0.523$, 95\% CI: 0.409-0.635, $\mathrm{p}=0.729$.

\section{Discussion}

Our results show a significant association between serum triglycerides and total amylin levels among pre-diabetics; findings that support the contention that hyperamylinemia may contribute to the pathogenesis of Type 2 Diabetes. Other reports observed increased circulating amylin levels in pre-diabetics $[1,22,23]$. However, in accordance with Butler et al., our results failed to observe any appreciable difference in amylin levels between pre-diabetics and control subjects [24]. Consequently, given that insulin and amylin levels positively correlate (data not shown), our findings would suggest that elevated circulating amylin levels may be related to the increased insulin secretion observed as a compensation for decreased insulin action; however, the exact form of amylin (reduced, unreduced, or amylin acid) which could be responsible remains elusive. Consistent with our proposal, amylin can act as a neuroendocrine hormone that complements the effects of insulin in postprandial regulation and there is evidence that in mice amylin improves leptin-mediated increases in insulin sensitivity [25]. As seen with our results, the unreduced (biological active) form failed to correlate with hypertriglyceridemia, indicating the mechanisms by which elevated levels of amylin may affect insulin action are unknown.

Studies on triglycerides and amylin in adult diabetics are scarce. However, infusion of amylin in rats lead to greater triglyceride content in liver and muscle tissue [10] and infusion of amylin-(8-37), a specific amylin antagonist, reduced muscle triglycerides concentration. On 
Citation: Porchia LM, Torres-Rasgado E, Gonzalez-Mejia ME, Perez-Fuentes R, Rivera A, et al. (2015) Serum Amylin Indicates Hypertriglyceridemia in Pre-diabetics. J Diabetes Metab 6: 509. doi:10.4172/2155-6156.1000509

Page 3 of 5

\begin{tabular}{|c|c|c|c|}
\hline & Total & Normal Glucose Tolerance & Impaired Glucose Tolerance \\
\hline Sample (M/F) & $140(60 / 80)$ & $81(34 / 47)$ & $59(26 / 33)$ \\
\hline Age (years) & $41.6 \pm 1.2$ & $36.2 \pm 1.3$ & $48.9 \pm 1.7^{*}$ \\
\hline Total Body Fat (\%) & $28.4 \pm 0.7$ & $27.2 \pm 1.0$ & $30.0 \pm 1.1$ \\
\hline Body Mass Index $\left(\mathrm{kg} / \mathrm{m}^{2}\right)$ & $26.2 \pm 0.4$ & $25.6 \pm 0.5$ & $27.0 \pm 0.6$ \\
\hline Systolic blood pressure (mmHg) & $114 \pm 1$ & $113 \pm 1$ & $117 \pm 1^{*}$ \\
\hline Diastolic blood pressure $(\mathrm{mmHg})$ & $75 \pm 1$ & $74 \pm 1$ & $76 \pm 1$ \\
\hline Fasting glucose (mg/dL) & $95 \pm 1$ & $89 \pm 1$ & $102 \pm 1^{*}$ \\
\hline Glucose 2-h postload (mg/dL) & $110 \pm 3$ & $99 \pm 2$ & $127 \pm 4^{*}$ \\
\hline Hemoglobin A1c (\%) & $5.03 \pm 0.04$ & $4.86 \pm 0.05$ & $5.21 \pm 0.06^{*}$ \\
\hline Fasting insulin $(\mu \mathrm{U} / \mathrm{mL})$ & $9.3 \pm 0.4$ & $8.7 \pm 0.5$ & $10.1 \pm 0.7$ \\
\hline Triglycerides (mg/dL) & $155.7 \pm 6.3$ & $149.4 \pm 8.4$ & $164.2 \pm 9.5$ \\
\hline Total Amylin (pM) & $7.6 \pm 0.3$ & $7.4 \pm 0.4$ & $7.8 \pm 0.4$ \\
\hline Reduced Amylin (pM) & $8.1 \pm 0.3$ & $7.6 \pm 0.4$ & $8.7 \pm 0.5$ \\
\hline
\end{tabular}

Table 1: Clinical and Metabolic characteristics Values are mean \pm standard error. Significance was determined by Student $T$ (Test. * $p<0.05$ Normal Glucose Tolerance vs. Impaired Glucose Tolerance).

A

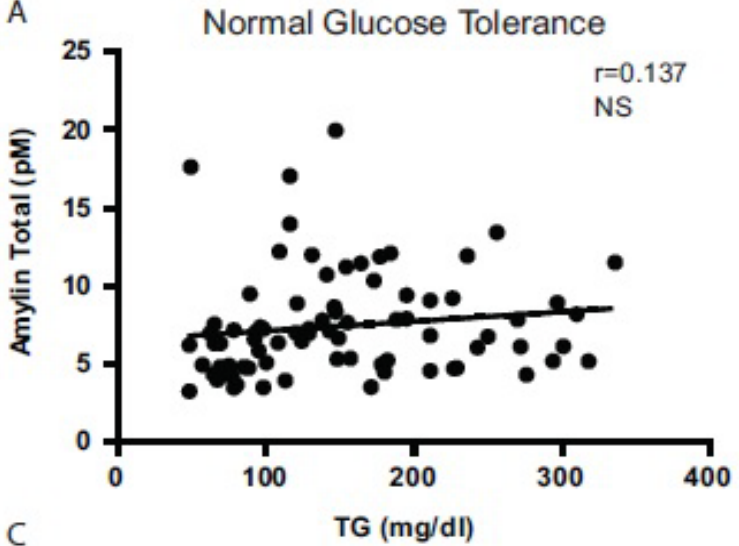

$c$

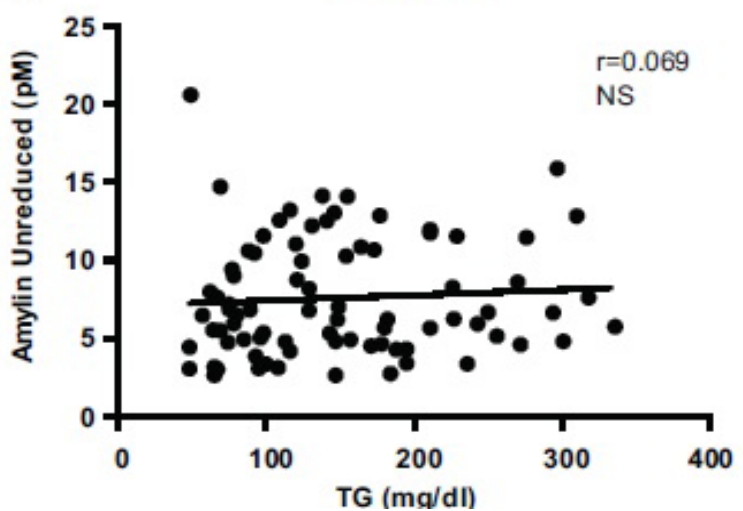

B Impaired Glucose Tolerance

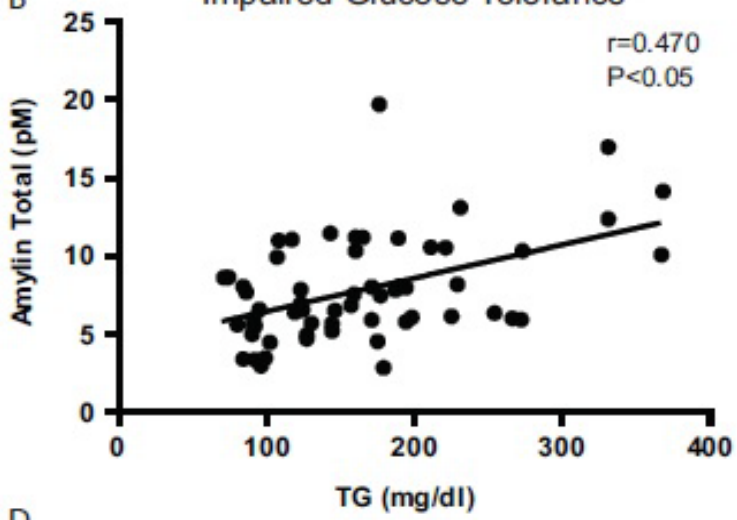

D

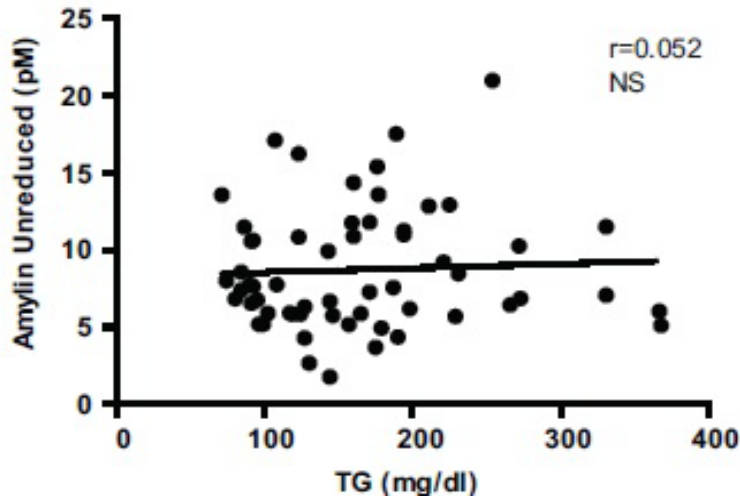

Figure 1: Correlation between triglycerides and amylin. The Pearson correlation coefficient ( $r$ ) was calculated between triglycerides and total amylin (A, B) or unreduced amylin $(C, D)$ for normal glucose tolerance subjects $(A, C)$ and impaired glucose tolerance subjects $(B, D)$.

the other hand, augmented plasma insulin enhanced muscle and liver insulin sensitivity and lowered plasma non-esterified fatty acids [15]. Studies in obese children showed that basal amylin levels were significantly correlated with insulin and triglycerides levels [6]. Interestingly, substantial weight loss in these children led to significant reduced amylin concentration that correlated with changes in insulin and triglycerides levels as well [8]. Percy et al. suggested that the different circulating forms of amylin (reduced and unreduced) or amylin-like molecules may have differential effects on the pathophysiology of Type 2 Diabetes [26]. Here, we determined that total amylin and not the unreduced form was associated with serum triglycerides. We posit that the reduced amylin may have an unknown role in insulin secretion and consequently in Type 2 Diabetes disease development.

Our study has a few limitations. First, the study is a cross-sectional study and cannot determine any causal effect between any of the forms of amylin and hypertriglyceridemia. Second, it is important to note that our study only included Hispanic subjects thus providing valuable information on the relationship between amylin and triglycerides among an ethnically uniform group of subjects. However, further research among adult populations of different ethnic origins are needed to clarify these relationships. Third, our subjects were only first-degree 
Citation: Porchia LM, Torres-Rasgado E, Gonzalez-Mejia ME, Perez-Fuentes R, Rivera A, et al. (2015) Serum Amylin Indicates Hypertriglyceridemia in Pre-diabetics. J Diabetes Metab 6: 509. doi:10.4172/2155-6156.1000509

Page 4 of 5

A

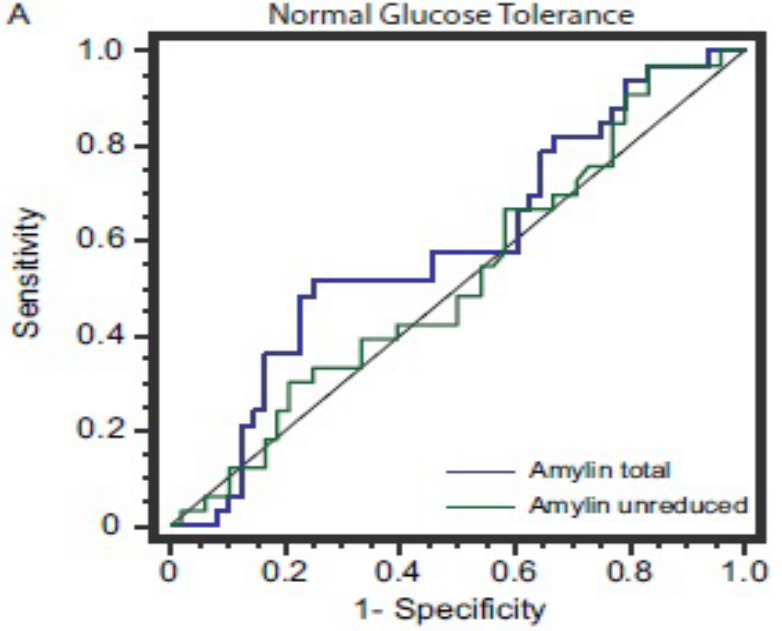

B

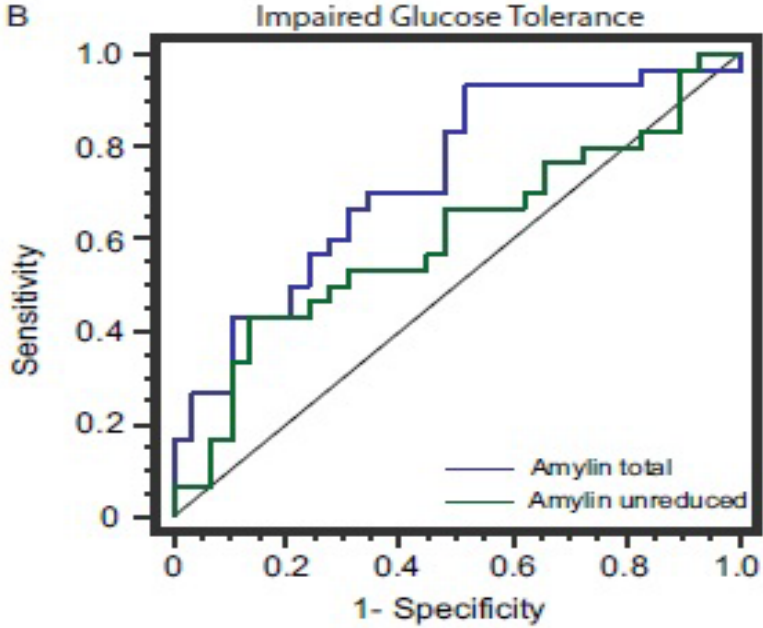

Figure 2: Receiver Operating Characteristic curve for normal glucose tolerance subjects (A) and impaired glucose tolerance (B) for detecting hypertriglyceridemia by total amylin (blue) or unreduced amylin (green).

relatives of Type 2 Diabetics. These results need to be confirmed among subjects without a genetics background for Type 2 Diabetes. Fourth, due to the size of the study, we were unable to determine the effects of obesity, hyperinsulinemia, or insulin resistance on amylin levels and hypertriglyceridemia.

In conclusion, our study suggests that serum triglycerides and total amylin levels are significantly associated in only pre-diabetics. Our study also supports the notion for examining reduced amylin and amylin-like molecules for their importance in Type 2 Diabetes development.

\section{Acknowledgements}

This study was supported in part by grants from the Programa de Mejoramiento del Profesorado (PROMEP) of the "Secretaria de Educacion Publica" and the "Vicerrrectoria de Investigación" of the Benemérita Universidad Autonoma de Puebla, Mexico (to ETR, MEGM and RPF), The IMSS Foundation CA (to FGR), The National Heart Lung and Blood Institute of the National Institutes of Health (USA) [R01 HL-096518] and a Harvard University Faculty Grant Award supported by the Banco Santander Fund of the David Rockefeller Center for Latin American Studies at Harvard University (to JRR). We would like to express our gratitude to the participants of this study and Ricardo Villegas-Tovar from BUAP Libraries Department. Finally, we would like to acknowledge Prof. María del Carmen Sánchez Guillén, MD, MSc, PhD who passed away and contributed to the development and implementation of this project. Her friendship, collegiality, talent, and creativity are sorely missed.

\section{References}

1. Westermark GT, Westermark $P(2013)$ Islet amyloid polypeptide and diabetes Curr Protein Pept Sci 14: 330-337.

2. Pillay K, Govender P (2013) Amylin uncovered: a review on the polypeptide responsible for type II diabetes. Biomed Res Int 2013: 826706.

3. Abedini A, Schmidt AM (2013) Mechanisms of islet amyloidosis toxicity in type 2 diabetes. FEBS Lett 587: 1119-1127.

4. Weyer C, Maggs DG, Young AA, Kolterman OG (2001) Amylin replacement with pramlintide as an adjunct to insulin therapy in type 1 and type 2 diabetes mellitus: a physiological approach toward improved metabolic control. Current pharmaceutical design 7: 1353-1373.

5. Pullman J, Darsow T, Frias JP (2006) Pramlintide in the management of insulin-using patients with type 2 and type 1 diabetes. Vasc Health Risk Manag 2: 203-212.

6. Reinehr T, de Sousa G, Niklowitz P, Roth CL (2007) Amylin and its relation to insulin and lipids in obese children before and after weight loss. Obesity (Silver Spring) 15: 2006-2011.

7. Cai K, Qi D, Hou X, Wang O, Chen J, et al. (2011) MCP-1 upregulates amylin expression in murine pancreatic $\hat{i}^{2}$ cells through ERK/JNK-AP1 and NF-Îم related signaling pathways independent of CCR2. PLoS One 6: e19559.

8. Sanke T, Hanabusa T, Nakano Y, Oki C, Okai K, et al. (1991) Plasma islet amyloid polypeptide (Amylin) levels and their responses to oral glucose in type 2 (non-insulin-dependent) diabetic patients. Diabetologia 34: 129-32.

9. Bronsky J, Prusa R (2004) Amylin fasting plasma levels are decreased in patients with osteoporosis. Osteoporosis international: a journal established as result of cooperation between the European Foundation for Osteoporosis and the National Osteoporosis Foundation of the USA 15: 243-247.

10. Ye JM, Lim-Fraser M, Cooney GJ, Cooper GJ, Iglesias MA, et al. (2001) Evidence that amylin stimulates lipolysis in vivo: a possible mediator of induced insulin resistance. Am J Physiol Endocrinol Metab 280: E562-569.

11. Qi D, Cai K, Wang O, Li Z, Chen J, et al. (2010) Fatty acids induce amylin expression and secretion by pancreatic beta-cells. Am J Physiol Endocrinol Metab 298: E99-99E107.

12. Ciaraldi TP, Goldberg M, Odom R, Stolpe M (1992) In vitro effects of amylin on carbohydrate metabolism in liver cells. Diabetes 41: 975-981.

13. Simental-Mendía LE, Rodríguez-Morán M, Simental-Saucedo L, GuerreroRomero F (2013) Insulin secretion is increased in non-diabetic subjects with fasting hypertriglyceridaemia. Diabetes Metab Res Rev 29: 214-219.

14. Beck-Nielsen H, Groop LC (1994) Metabolic and genetic characterization of prediabetic states. Sequence of events leading to non-insulin-dependent diabetes mellitus. The Journal of clinical investigation 94: 1714-1721.

15. Hjellvik V, Sakshaug S, Strøm H (2012) Body mass index, triglycerides glucose, and blood pressure as predictors of type 2 diabetes in a middle-aged Norwegian cohort of men and women. Clin Epidemiol 4: 213-224.

16. Nguyen QM, Xu JH, Chen W, Srinivasan SR, Berenson GS (2012) Correlates of age onset of type 2 diabetes among relatively young black and white adults in a community: the Bogalusa Heart Study. Diabetes Care 35: 1341-1346.

17. Hettiarachchi M, Chalkley S, Furler SM, Choong YS, Heller M, et al. (1997) Rat amylin-(8-37) enhances insulin action and alters lipid metabolism in normal and insulin-resistant rats. Am J Physiol 273: E859-867.

18. Expert Committee on the Diagnosis and Classification of Diabetes Mellitus (2003) Report of the expert committee on the diagnosis and classification of diabetes mellitus. Diabetes Care 26 Suppl 1: S5-20.

19. Ministry of Health M (2002) Norma Oficial Mexicana NOM-037-SSA2-2002, "Para la prevención, tratamiento y control de las dislipidemias".

20. American Diabetes Association (2012) Diagnosis and classification of diabetes mellitus. Diabetes Care 35 Suppl 1: S64-71.

21. Hanley JA, McNeil BJ (1982) The meaning and use of the area under a receiver operating characteristic (ROC) curve. Radiology 143: 29-36.

22. Zheng X, Ren W, Zhang S, Liu J, Li S, et al. (2010) Serum levels of proamylin 
Citation: Porchia LM, Torres-Rasgado E, Gonzalez-Mejia ME, Perez-Fuentes R, Rivera A, et al. (2015) Serum Amylin Indicates Hypertriglyceridemia in Pre-diabetics. J Diabetes Metab 6: 509. doi:10.4172/2155-6156.1000509

Page 5 of 5

and amylin in normal subjects and patients with impaired glucose regulation and type 2 diabetes mellitus. Acta Diabetol 47: 265-270.

23. James S, Moralez J, Nagamani M (2010) Increased secretion of amylin in women with polycystic ovary syndrome. Fertil Steril 94: 211-215.

24. Butler AE, Jang J, Gurlo T, Carty MD, Soeller WC, et al. (2004) Diabetes due to a progressive defect in beta-cell mass in rats transgenic for human isle amyloid polypeptide (HIP Rat): a new model for type 2 diabetes. Diabetes 53: 1509-1516.
25. Kusakabe T, Ebihara K, Sakai T, Miyamoto L, Aotani D, et al. (2012) Amylin improves the effect of leptin on insulin sensitivity in leptin-resistant diet-induced obese mice. Am J Physiol Endocrinol Metab 302: E924-931.

26. Percy AJ, Trainor DA, Rittenhouse J, Phelps J, Koda JE (1996) Development of sensitive immunoassays to detect amylin and amylin-like peptides in unextracted plasma. Clin Chem 42: 576-585. 